\title{
A Developmental Study on Types and Frequency Distribution of Short Apneas (3 to 15 Seconds) in Term and Preterm Infants ${ }^{1}$
}

\author{
DAVID LEE, REBECCA CACES, KIM KWIATKOWSKI, DON CATES, AND HENRIQUE RIGATTO \\ University of Manitoba, Department of Pediatrics, Section of Neonatal Medicine, Women's Hospital, \\ Winnipeg, Manitoba, R3E OL8 Canada
}

\begin{abstract}
We measured the frequency distribution and the ventilatory correlates of the various types of apneas 3 to $15 \mathrm{~s}$ long during sleep in eight term infants (birth weight $3.65 \pm 0.16 \mathrm{~kg}$; gestational age $39.5 \pm 0.3 \mathrm{wk}$ ) and eight preterm infants (birth weight $2.07 \pm 0.18 \mathrm{~kg}$; gestational age $34.3 \pm 0.4 \mathrm{wk}$ ). Each infant was studied on five to seven occasions from birth to $56 \mathrm{wk}$ of postconceptual age using a modified flow-through system. Sixty-six paired epochs of quiet sleep (1163 min) and rapid eye movement sleep $(829 \mathrm{~min})$ were analyzed in term infants and 85 paired epochs of quiet sleep $(1553 \mathrm{~min})$ and rapid eye movement sleep $(1328 \mathrm{~min})$ in preterm infants. Of the 783 apneas recorded in term infants $82 \%$ were central, $1.5 \%$ obstructive, $0.5 \%$ mixed, and $16 \%$ were of the breath-holding type; the corresponding figures for the $\mathbf{4 0 8 6}$ apneas recorded in preterm infants were $93,0.5,1.0$, and $5.5 \%$. This distribution was similar in the two sleep states but term infants had a higher percentage of breath-holding apneas than preterm infants $(p<0.01)$. In preterm infants the rate of central apneas decreased with postnatal age $(p<0.01)$; in term infants the rate did not change significantly. The duration of apneas showed a modal distribution for central apneas at about $8 \mathrm{~s}$ for both groups during the 1st month of life $(p<0.05)$. The findings suggest: 1$)$ apneas in the newborn and early infancy are primarily central and are more frequent in preterm than in term infants; 2 ) the higher rate of apnea in healthy preterm infants is accounted for almost entirely by the higher rate of central apneas; 3) a significant decrease in the rate of apnea occurs during the first 4 months after birth; and 4) preterm infants show longer respiratory pauses in both quiet sleep and rapid eye movement sleep when compared to term infants, and a maturation pattern can be discerned by 3 months of age. (Pediatr Res 22: 344-349, 1987)
\end{abstract}

\section{Abbreviations}

$\mathrm{V}_{\mathrm{E}}$, minute ventilation

$V_{\text {T }}$, tidal volume

f, respiratory frequency

$\mathrm{P}_{\mathrm{A}} \mathrm{CO}_{2}$, end-tidal $\mathrm{PCO}_{2}$

$\mathrm{P}_{\Lambda} \mathrm{O}_{2}$, end-tidal $\mathrm{PO}_{2}$

QS, quiet sleep

REM, rapid eye movement sleep

$\mathrm{T}_{\mathrm{C}} \mathrm{PO}_{2}$, transcutaneous $\mathrm{PO}_{2}$

Received October 2, 1986; accepted April 20, 1987

Correspondence Dr. Henrique Rigatto, The University of Manitoba. Department of Pediatrics, Room WSI08 Women's Hospital, 735 Notre Dame Avenue. Winnipeg, Manitoba R3E OL8 Canada.

Supported by The Medical Research Council of Canada Grant MT-4980 and

The Children's Hospital of Winnipeg Research Foundation.

'Presented in part at the FASEB meeting, Anaheim, CA April 1985
$\mathrm{EMG}_{\mathrm{Di}}$, electromyogram of the diaphragm

BW, birth weight

GA, gestational age

ANOVA, analysis of variance

SIDS, sudden infant death syndrome

Although long and potentially pathologic apneas of more than $20 \mathrm{~s}$ in duration have been frequently studied, there is little known about the developmental pattern of shorter apneas of 3 to $15 \mathrm{~s}(1-6)$. There is increasing evidence that the presence of these short apneas reflect a disturbance of the respiratory control system which may lead to longer apneas and to SIDS (7-10). Furthermore, there are a paucity of data on the prevalence of the various types of apnea during the neonatal period and early infancy. The change in frequency distribution of these apneas with age and in different sleep states has not been determined.

We designed this study therefore to determine the types of apneas 3 to $15 \mathrm{~s}$ long and their frequency distribution according to sleep state at the various gestational and postnatal age.

\section{SUBJECTS}

Eight term infants [BW $3.65 \pm 0.16 \mathrm{~kg}$ (SE); GA $39.5 \pm 0.3$ wk] and eight preterm infants (BW $2.07 \pm 0.18 \mathrm{~kg}$; GA $34.3 \pm$ $0.4 \mathrm{wk}$ ) were studied after informed consent was obtained from one or both parents. All infants were born at the Women's Hospital, Winnipeg. Term babies had normal antenatal and postnatal course. Mothers of the preterm babies had various forms of complications during the last trimester. However, none of their babies showed any degree of asphyxia at the time of birth. None had evidence of intracerebral hemorrhage and all were neurologically normal on follow-up. All babies grew and developed normally for the duration of the study, and remained normal at 1 yr of age by telephone enquiry.

\section{METHODS}

Polygraphic recording was done on five to seven sessions in each infant. Infants breathed a mixture of $21 \% \mathrm{O}_{2}$ in $\mathrm{N}_{2}$ during the study. Term infants were studied within the 1 st wk of birth and then at 4-wk intervals until the postconceptual age of $56 \mathrm{wk}$. Preterm infants were studied at 2 -wk intervals during the ist month and then at 4-wk intervals until the postconceptual age of 52 to $56 \mathrm{wk}$. All sleep-monitoring sessions were carried out in a neonatal respiratory laboratory. The babies slept in a supine position on an Ohio Neonatal Intensive Care Unit, shortly after a feed. The ambient temperature was kept at the thermal neutral range and skin temperature remained at $36.5 \pm 0.03^{\circ} \mathrm{C}$. 
Details of instrumentation and measurements have been described previously $(11,12)$. Briefly. ventilation was measured using a nose-piece and a flow-through system (1.3). Inspiratory flow was integrated to give volume. Breath-to-breath (), and (C). concentrations were measured continuously by sampling at one of the nostrils (Beckman (), and (O), analyers). TCP(), (Narco Scientific Itd.) and (), saturation (Biox II Gar (Oxvmeter) were also continuously recorded. I:M(;)i was recorded with surface electrodes. (hest and abdominal excursions were monitored by mercury strain gauge (11). Filectrocardiogram was monitored using standard leads.

Sleep states were defined as previously $(11,14)$. The definition depended on monitored LI: ; (F-4-Al leads). eve movements. and behavior. Movements of the eves were recorded by two leads placed one superior to the keft outer canthus and one inferior to the right outer canthus, both referenced to the right pinna. Behavioral changes as well as visible rapid eve movements were charted on the continuous readout tracing. Signals were filtered. amplified. and recorded on a multichannel EE( $\mathrm{z}$ recorder (Nihon Kohden Inc.) and also stored on magnetic tape for future analysis. For each study the behavioral state of the infant was classified into periods (epochs) of recognizable wakefulness. QS. RE:M. transitional state, and indeterminate state. Wakefulness was defined by eyc opening and restlessness, with or without cring. QS was defined by eve closure in the presence of high voltage EE(i activity or "frace alternans," and the absence of eve movement and general body movement except for occasional myoclonic jerks ("startles"). RIEM was defined by the presence of rapid eye movements during sleep, irregular low voltage fast FEG activity, and frequent jerking movements of the body. As in previous studies $(15)$ we avoided using respiratory pattern as a basis for defining sleep states. Transitional states were periods "Sandwiched" hetween QS and REM without wakefulness. Periods that could not be thus classified were deemed indeterminate.

Of the five behavioral states. QS and RFM epochs were further analyzed for the ventilatory variables and the presence of apneas of 3 to $15 \mathrm{~s}$ in duration. For each epoch. we calculated $V_{1}$. f $V_{1}$.

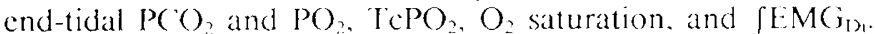
These variables were meant to define the ventilatory correlates of each state and served as independent assessment of slecp states. A representative tracing is shown in ligure 1.

The respiratory pauses, identiticed by the eessation of nasal air flow for 3 to 15 s not associated with gross hody movements or stretching. were chassified inte one of four categories: 1) central apnea: an expiratory pause during which no respiratery output could be detected in the form of $\mathrm{E}: \mathrm{M}\left(\mathrm{i}_{\mathrm{D}}\right.$. chest oi abdominal excursions: 2) obstructive apnea: a pause in nasal flow with persistent EM( $i_{1}$, activity and chest and abdominal excursions: 3) mixed apnea: pauses with clements of central and obstructive apneas: and 4) breath-holding apnea: an expirators pause that is terminated by an expiration before the next breath (1:ig. 2).

Statistical analysis consisted of parring adjacent cpochs of QS and REM in order to reduce the intrastudy variability (16). In cight term infants 66 patred epochs of QS (total duration 116,3 min) and REM (829 min) were analyzed. while in the cight preterm infants 85 pairs were identified (QS. 1553 min: RI:M. $1328 \mathrm{~min}$ ). The proportion of QS and REM were not different in the two groups.

For each epoch the rate of each type of apnea was cepressed as number per h. Since apnea rate $(r)$ had a non-(ialussian distribution a logarithmic transformation $[\mathrm{I} n(\mathrm{r}+1)]$ was performed to normalize the data before comparing the means using the two-tailed paired / test. A p value of less than (0.) s was considered to be significant. ("hi-square was used to detect differences in the proportion of the different types of apneas. Splitplot A.VOVA was used to examine the effects of posteonecptional age and sleep state on the rate of apneas and other respiratory measurements. Individual comparisons were then mate using the least squares means test. The duration of the apneas showed a continuous distribution between 3 and $15 \mathrm{~s}$. The relationship between rate and duration of apnea was examined using least squares curve fitting procedures (17).

\section{RESUIITS}

A total of 783 apneas was recorded in term infants and 4086 in the preterm infants. Of these. central apneas predominated. accounting for $82 \%$ of the total in term infants and $93 \%$ in preterm (Table 1. Fig. 3). The next most freguent type was the

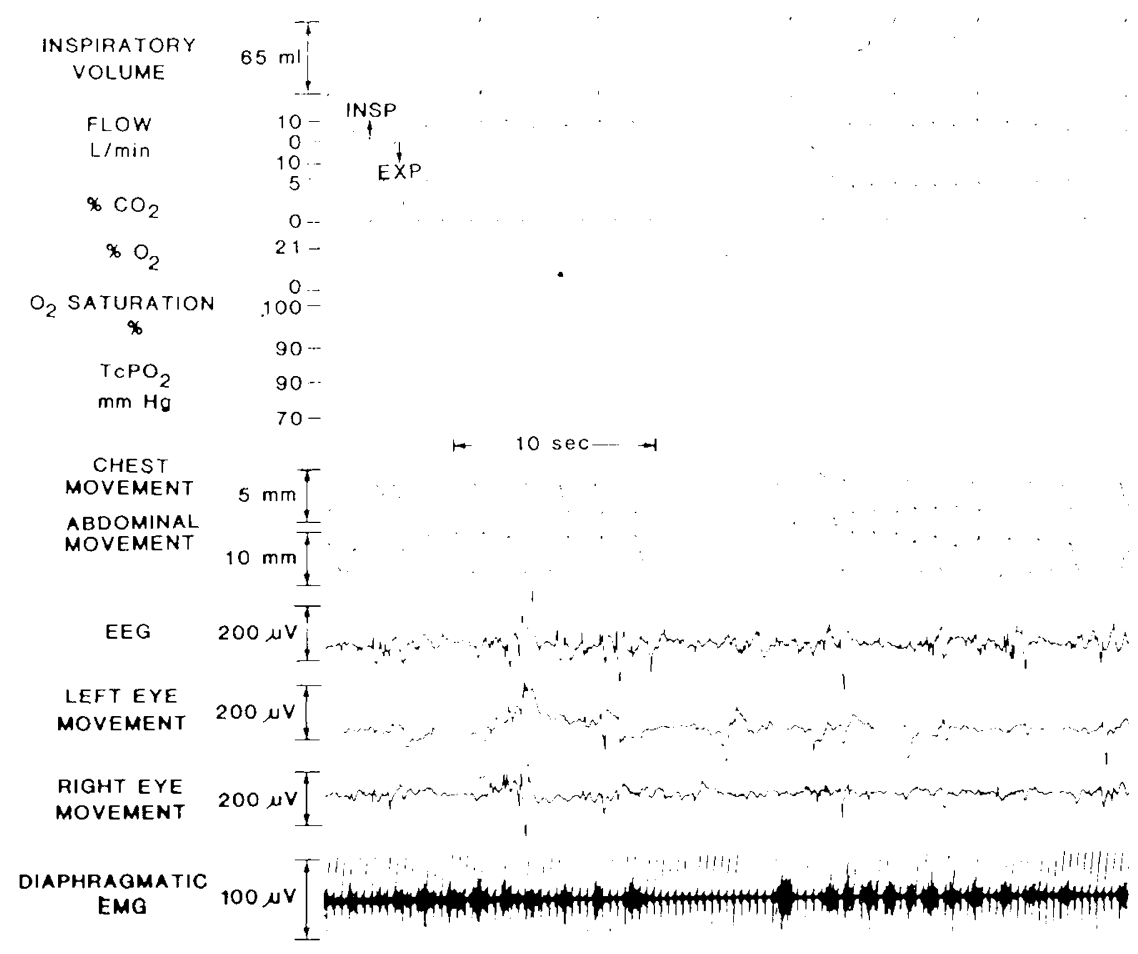

Fig. 1. Representative tracing during REM sleep in a preterm infant ( 33 wk gestation) at 25 days of age. 


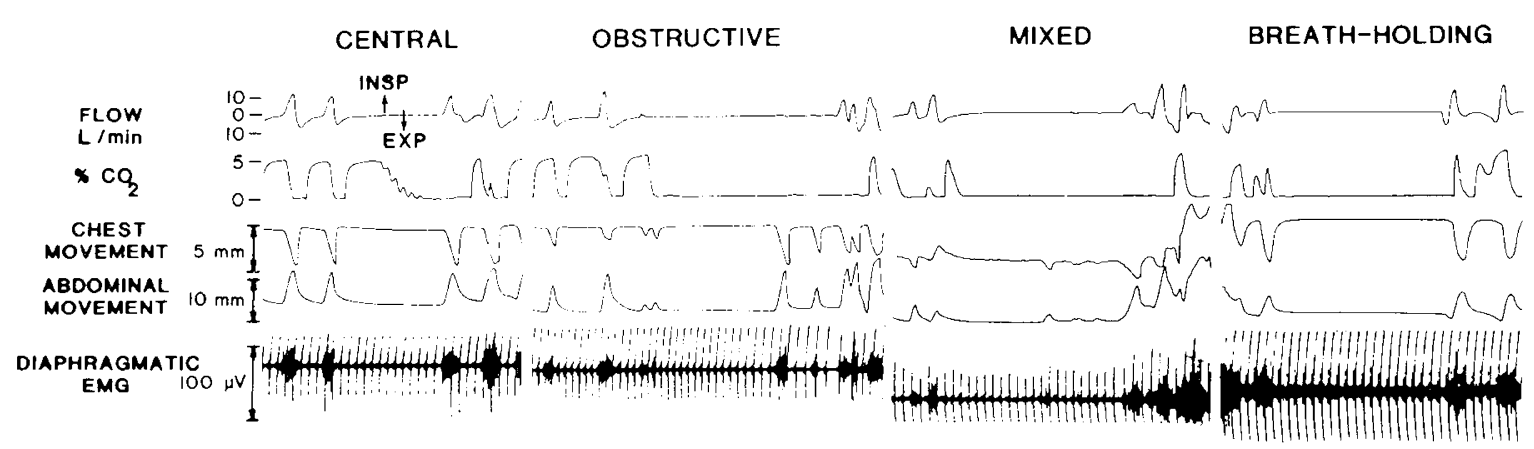

Fig. 2. Classification of apneas. Apneas were defined by the absence of nasal airflow and the absence (central type) or presence (obstructive type) of diaphragmatic activity and corresponding chest and abdominal movements. Mixed apneas showed both central and obstructive features. In breath-holding type the expired breath was delayed until just before the next inspiration.

breath-holding apnea which was more prevalent in the term group accounting for $16 \%$ of the total; only $5.5 \%$ of the apneas in the preterm group belonged to this type $(p<0.02)$. The other two types of apneas accounted for less than $3 \%$ of the total number of apneas. There was no difference between sleep states regarding this distribution.

Preterm infants had a significantly higher rate of central apneas in both sleep states than term infants ( $p<0.01$; Fig. 4). In preterm infants the rate fell rapidly postnatally; by $44 \mathrm{wk}$ of postconceptional age it was comparable to that of term infants. After 44 wk there was a divergence in the rate of central apneas between the two sleep states, the rate during REM being higher at $47 \mathrm{wk}$ and at $54 \mathrm{wk}(p<0.05)$. In term infants the change in rate of central apneas with increasing postnatal age was less pronounced and not significant. In these infants the mean rate of apneas in QS increased from an initial value of $9 / \mathrm{h}$ at 3 days to $24 / \mathrm{h}$ at $4 \mathrm{wk}$ of age, and then decreased gradually over the next 2 to 3 months to levels below the initial value. In REM, a similar trend was observed during the 1 st month. Again, after 44 wk of postconceptional age there was a divergence in the rate of apneas between the two sleep states in term infants, the rate becoming significantly higher in REM sleep at $48 \mathrm{wk}(p<0.05)$. The rate of breath-holding apneas in term infants decreased with age from $7 / \mathrm{h}$ at $40 \mathrm{wk}$ to $0.5 / \mathrm{h}$ at $48 \mathrm{wk}$ of postconceptional age $(p<0.01)$ and from $10 / \mathrm{h}$ at $35 \mathrm{wk}$ to $0.9 / \mathrm{h}$ at $47 \mathrm{wk}(p<0.05)$ in preterm.

The duration of apneas was arbitrarily classified into intervals of $1 \mathrm{~s}$ (from 3 to $15 \mathrm{~s}$ ) and the relationship between rate and duration was examined for central and breath-holding apneas. The longest apnea lasted for $15 \mathrm{~s}$. For both term and preterm infants non-Gaussian distributions were obtained in both sleep states during the 1 st and the $3 \mathrm{rd}$ month of life (Fig. 5). In preterm infants at 1 month of postnatal age, the distribution of rates of central apneas during QS demonstrated a modal tendency at around $8 \mathrm{~s}$ both in REM and in QS. Using least squares curve fitting procedures (17) the data were fitted to a combined quadratic curve (describing the primary decreasing rate/apnea duration relationship) and normal curve (describing the secondary peaked relationship present at duration of 6 to $10 \mathrm{~s}$ ). The fit was excellent $(p<0.001)$ and the composite model accounted for $99.4 \%$ of the observed variation. The secondary normal curve had a peak at $8.13 \mathrm{~s}$. At 3 months of age during REM and QS, the data also fitted quadratic models $(p<0.001)$ but a secondary peak was absent. Similarly, in term infants the data on central apneas fitted a composite quadratic/normal model at 1 month of age in QS $(p<0.001)$ and accounted for $92.9 \%$ of the observed variation. The peak for the secondary normal distribution was at $7.94 \mathrm{~S}$. In REM sleep at 1 and 3 months and in QS at 3 months the data fitted quadratic models $(p<0.001)$ but a secondary peak was absent.

In preterm infants at 1 month of age, the distribution of breathholding apneas during QS also fitted a composite quadratic/ normal curve model $(p<0.001)$, which accounted for $84.0 \%$ of the observed variations. The peak for the secondary normal curve was at $8.05 \mathrm{~s}$. At 1 month of age in REM sleep the data also fitted a composite model $(p<0.001)$ but a secondary peak was absent. At 3 months the breath-holding apneas were too few to be subjected to statistical analysis. In term infants the frequency of breath-holding apneas was also low for statistical analysis.

There was no significant change in $V_{E}$ over the period of the study but values in REM were significantly higher than those in QS for all ages $(p<0.05)$ (Table 1, Fig. 6). This was due primarily to a higher $\mathrm{f}$ in $\operatorname{REM}(p<0.05)$ in the preterm group with $\mathrm{V}_{\mathrm{T}}$ remaining unchanged between the states. In term infants the higher $V_{E}$ in REM was also primarily attributed to an increase in $\mathrm{f}$, but $\mathrm{V}_{\mathrm{T}}$ was also significantly larger at 48 and $52 \mathrm{wk}$ of postconceptional age. $\mathrm{P}_{\mathrm{A}} \mathrm{CO}_{2}$ remained unchanged in both groups of infants over the period of study as was $\mathrm{TcPO}_{2}$ in term infants. $\mathrm{TcPO}_{2}$ in the preterm group showed a significant increase with age, from $60 \mathrm{~mm} \mathrm{Hg}$ at $37 \mathrm{wk}$ postconceptional age to 77 $\mathrm{mm} \mathrm{Hg}$ at $47 \mathrm{wk}$ postconceptional age $(p<0.05)$.

\section{DISCUSSION}

We examined the frequency distribution of the various types of short apneas ( 3 to $15 \mathrm{~s}$ ) during the first 3 months of life in healthy preterm and term infants. We found that central apneas predominated, obstructive, or mixed apneas being rare. Breathholding apneas, surprisingly, were relatively common in term infants. The distribution of apneas according to length was continuous showing a modal tendency at about $8 \mathrm{~s}$ in preterm infants during the 1st month of life. Despite the high prevalence of apneas, particularly in the preterm group of infants, ventilatory correlates remained remarkably unchanged. Sleep states affected the prevalence of apneas only after $44 \mathrm{wk}$ of postconceptional age. The findings suggest that oscillations of the respiratory control system producing short apneas during early postnatal life are common. Because they are more frequent in preterm than in term infants, we suggest that they reflect immaturity of the respiratory control system, possibly involving the respiratory "centers" and the peripheral mechanical properties of the respiratory pump.

The frequency distribution of short apneas has not been examined sequentially during the early neonatal period. We were surprised to see that they are commonly seen also in term infants. Kelly and Shannon (18) suggested that the presence of apneas in term infants increases the risk of SIDS. Steinschneider (19) suggested that early neonatal apnea was commonly followed by SIDS. In subsequent reports this investigator examined the frequency of apneas in neonates and used discriminant analysis to identify a population at risk for SIDS. The present study specifically examined short apneas longitudinally in preterm and term infants. Sleep state did not affect the incidence or rate of apnea before $44 \mathrm{wk}$ of postconceptional age. This observation was 


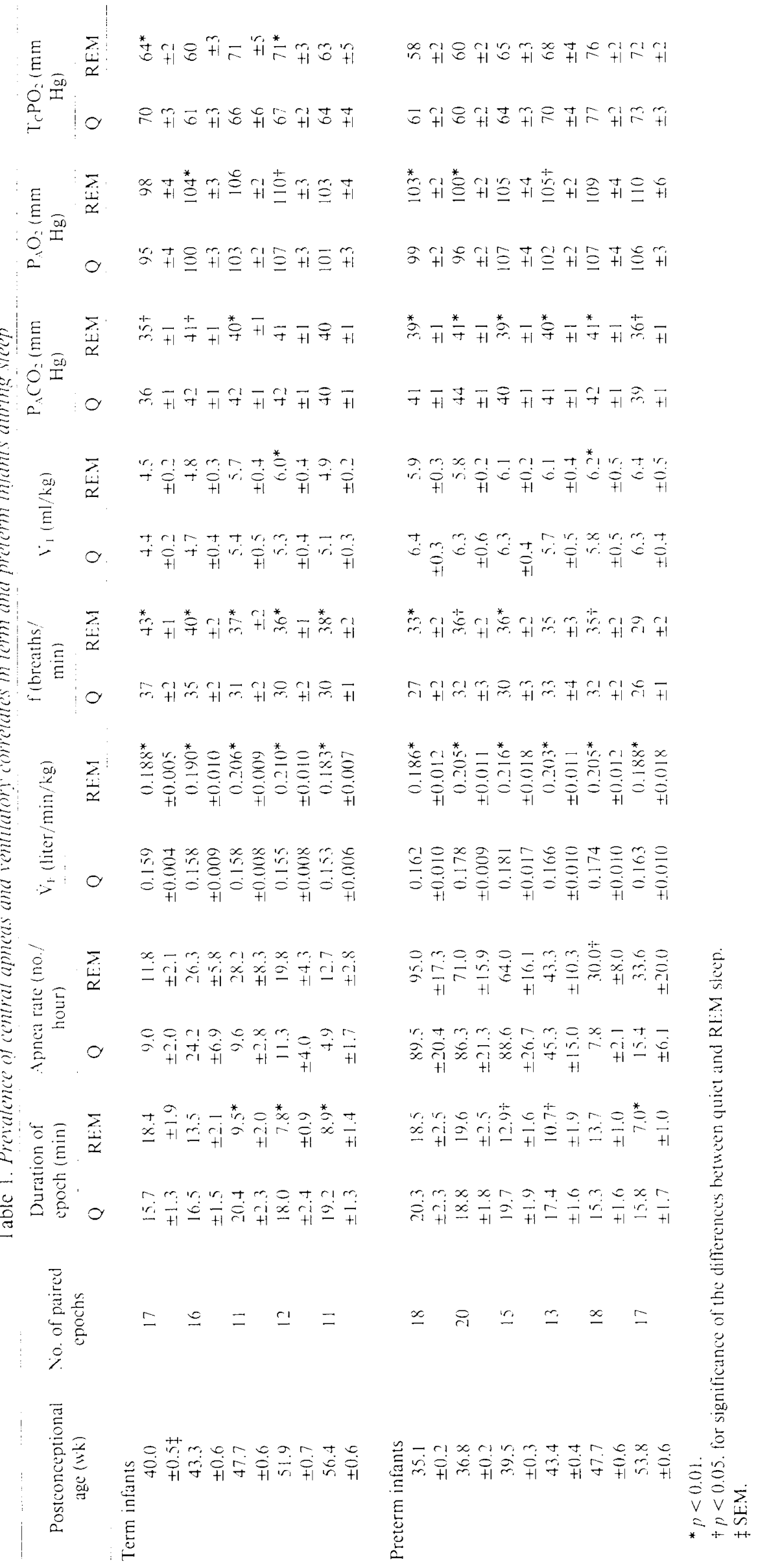



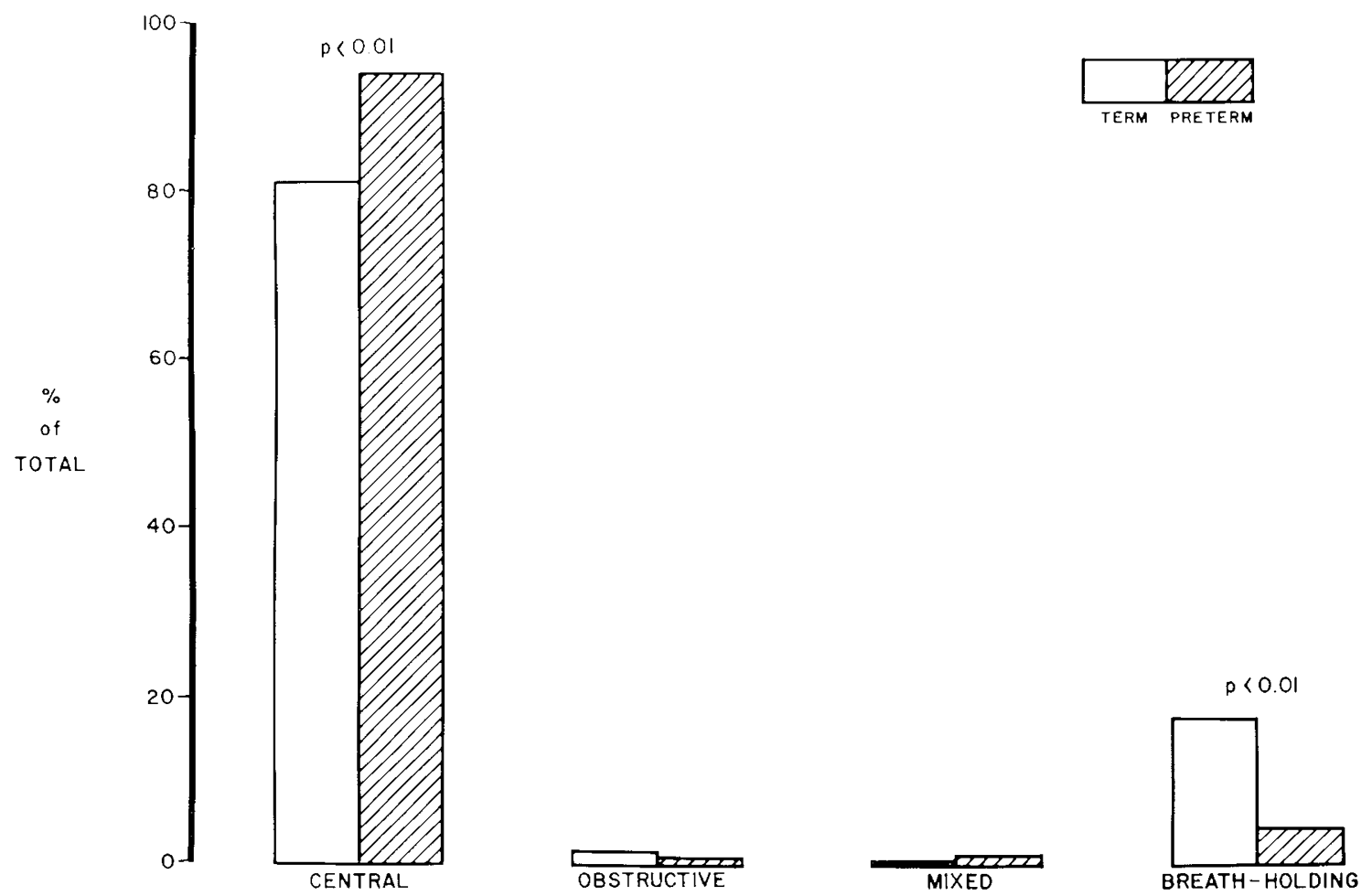

Fig. 3. Prevalence of various types of apneas. Central apneas predominated. Next in prevalence were breath-holding type of apneas. Obstructive and mixed apneas were rare.

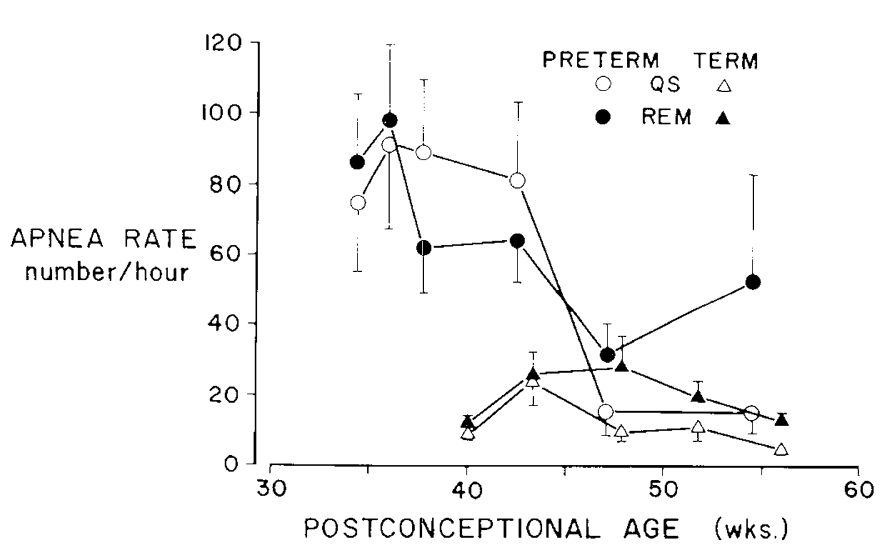

Fig. 4. The effect of postnatal age on the rate of central apneas. The rate of apneas decreased with postnatal age in preterm infants but did not change in term infants. After 44 wk of postconceptional age apneas were more frequent in REM than in quiet sleep both in term and preterm infants.

interesting, considering that REM sleep is frequently quoted as being associated with more apneas than QS $(1,9,20)$. The reason for this lack of difference is unknown, but we would like to speculate that the inherent imbalance of the respiratory control system at this early age, may preclude the appearance of differences related to sleep states. In favor of this hypothesis is the similarity in the distribution of duration of apnea in the term and preterm groups, independent of sleep state. The modal tendency at about $8 \mathrm{~s}$ appearing in preterm infants only, probably reflects the increased instability of the respiratory control system in this group of infants. This increased imbalance may be consequence of their relative hypoxemia, for example. Previous work in the area of apnea, periodic breathing, and respiratory control suggest that these short apneas are likely related to the oscillations in arterial blood gases (21). Waggener et al. (10) suggested that prolonged apneas have the same etiology as short apneas.
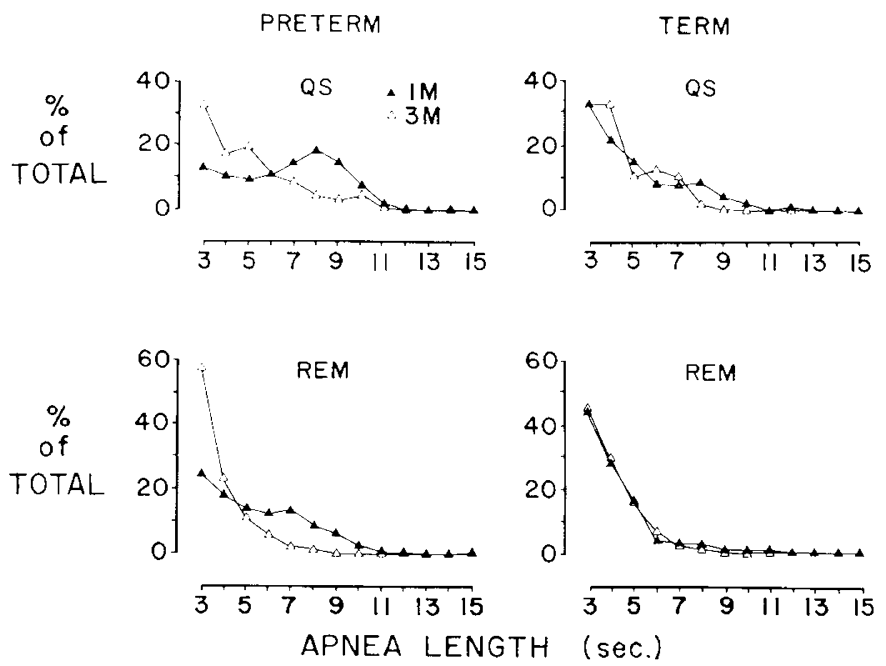

Fig. 5. Frequency distribution of central apneas at 1 and 3 months of postnatal age. Apneas were longer during the Ist month than during the 3 rd month in preterm infants $(p<0.005)$. This difference disappeared at 3 months of age.

Our classification of the types of apnea followed conventional terminology present in the literature $(7,22-24)$. Two major findings were of interest. First, the predominance of central apneas both in term and preterm infants argues against a major role for peripheral mechanisms on the cause of apnea in healthy infants. In infants recovering from RDS the prevalence of mixed apneas is greater than in the present study and is likely related to residual lung disease (22). Second, the large percent of breathholding apneas in term infants suggest an important underlying control element which is missing in preterm infants. Breathholding apneas may represent activation of laryngeal adductors while the short burst of expiratory flow following apnea represents abductor activation. Adductor activity such as that of the thyroarytenoid muscle, is abolished in REM sleep (25-27). Be- 


\section{PRETERM INFANTS}
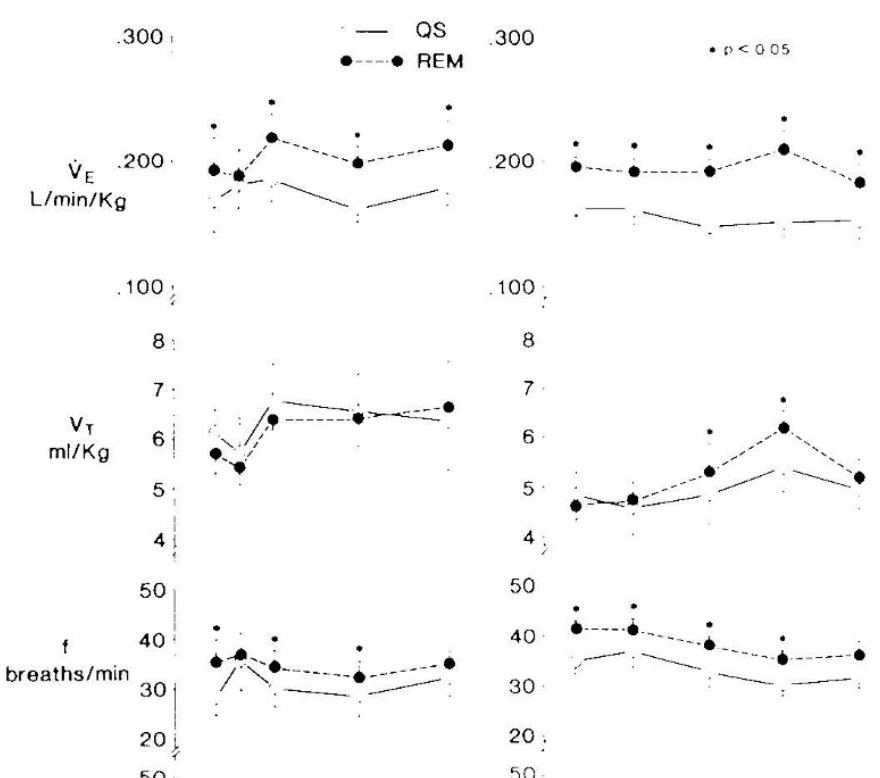

100

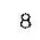

7.

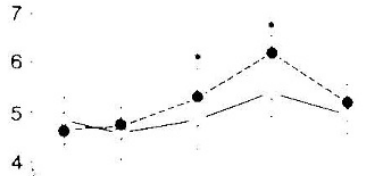

4

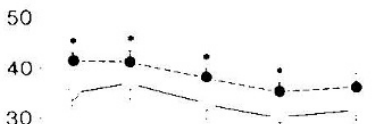

20:

50

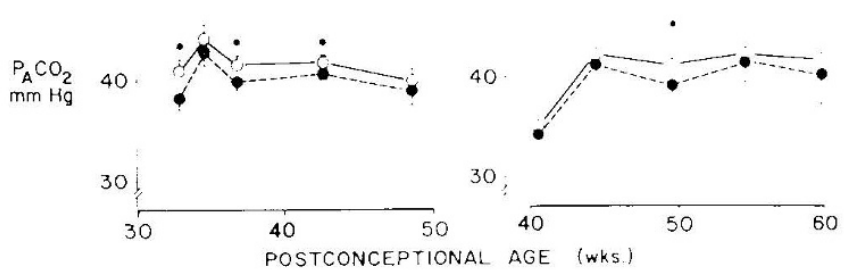

Fig. 6. The effect of post natal age on ventilatory variables. Ventilation did not change with postnatal age despite major change in respiratory pattern both in term and preterm infants.

cause preterm infants spend most of their time in REM sleep, it is possible that the mechanism controlling breath-holding apneas is inactive most of the time.

$V_{1}$ remained remarkably stable despite the oscillating nature of breathing pattern. Previously, we suggested that infants having periodic breathing and apnea had lower $V_{1}$ than those breathing regularly (2). Those were infants in whom apneas were long. usually more than $15 \mathrm{~s}$ and frequently more than $20 \mathrm{~s}$ duration. In that same report we suggested that in a system oscillating between apnea and breathing periods. the resulting respiratory $V_{\mathrm{E}}$ would greatly depend on the ventilation/apnea ratio. If this ratio is more than 2 , hyperventilation occurs in relation 10 regular breathing; if less, hypoventilation results. In the present investigation we studied short apneas, the ventilation/apnea ratio therefore being more than 2. Under these circumstances $V_{1}$ tended to remain unchanged as breathing became regular with an increase in postnatal age. Alveolar ventilation was also stable as reflected by unchanged alveolar $\mathrm{P}\left(\mathrm{O}_{2}\right.$. Trancutaneous $\mathrm{PaO}$, tended to increase with age in preterm infants, probably reflecting large $V /$ Q abnormalities which improved with age (28).

In conclusion, we measured the frequency distribution of short apneas in preterm and term infants during sleep during the early postnatal period. Central apneas predominated in preterm and term infants, but breath-holding apneas accounted for $16 \%$ of the apneas in term infants and only $5.5 \%$ in preterm infants. Obstructive and mixed apneas were rare. The rate of apneas decreased with postnatal age to a level that was statistically the same in preterm and term infants at 3 months of age. Sleep state did not affect the prevalence of short apneas before $44 \mathrm{wk}$ of gestation and ventilation remained unchanged despite a decrease in the prevalence of apnea with age. The findings suggest that short apneas are common in these newborn infants. more so in preterm than in term infants. and are likely to represent a baseline instability of the respiratory control system at this age.

1cknowledgements. The authors thank Debbie Bialek for her invaluable help in preparing and typing the manuscript. We also thank Tom Hassard and Mary Cheang for their help with the statistical analysis.

\section{RIFHRENC HS}

1. Cabriel M. Alhani M. Schulte FJ 1976 Apneic spells and sleep states in preterm infants. J Pediatr $57: 1+2-147$

2 Rigatto If Brady JP 1972 Periodic breathing and apncat in proterm intants 1 Evidence of hypoventilation possibly due to central respitatory depeesson. Pediatries $50: 20) 2-218$

3. Rigatto H. Brady JP 1972 Pcriodic hreathing and apnea in preterm infants. H. Hypoxia as a primary esent. Pediatrics $50: 219 \ldots 228$

4. Daily WJR, Klaus M. Mever HBP 1960 Apnea in premature intants: Montoring incidence, heart rate changes and effects of envirommental temperature Pediatrics $43.510-518$

5 Schulte FJ 1977 Apnca. (lin Perinatel $4: 65-76$,

6. Steinschneider A 1972 Prolonged apmea and the sudden intam death syndrome: clinical and laboratory observations. Pediatrics $50: 6.40-6,54$

7. Wealthall $\$ 1983$ The natural history of short breathing pauses dust Patediatr J 19:262(abstr)

8. Kefly I)H. Shannon $D($ 1979) Periodic heathing in infants with near-miss sudden infant death syndrome. Pediatries $6.3: 355-3606$

9. (juilleminault ( . Ariagno R. Korobkin R. Vagel I. Baldwin R. ('oons S. ()wen M 1979 Mixed and obstructive slecp apnea and near miss for sudden infant death syndrome: 2. Comparison of near miss and normal control intants by age. Pediatrics $64: 882-89)$

10. Waggener TB. Stark AR. (ohlan B.A. Frante III II) I9S4 Apnea duration is related to ventilatory oscillation characteristics in newhorn infants. I Appl Physiol 57:536-5.4

11. Moriette (; Van Reempts P. Moore M, (ates D). Rigatto H 1985 the offect of rebreathing ( $\left.{ }^{\circ}\right)$, on ventilation and diaphragmatic dectromyongaphy in newhorn intants. Respit Physiol 62:387-397

12. Aizad I. Bodani J. (ates I), Horvath 1. Rigatto H l984 fifect of a single breath of 100$)^{c}$; oxygen on respiration in meomates during steep. I Appl Physiol 57:153!-1535

13. Rigatto 11. Brady JP 1972 A new nosepece for measuring contilation in preterm infants. 5 Appl Physiol 32:42:3-424

4. Prechtl HIFR 1974 The behavioural states of the newhorn infant (at review). Brain Res $76: 185-21$ ?

15. Rigatto H, Kalapesi Z. Leahy Fl, Durand M Mac( allum M, (atces I) 1980 (hemical control of respiratery frequency and tidal wolume during slecp in preterm infants. Respir Physiof $+1: 117-125$

16. Miller JC. Horvath SM 1976 (ardiac output during human slecp. Aviat Space Environ Med 47:1040-1051

17. Kleinbaum [X) Kupper I.I. Morgenstern H 1982 Epidemiologere Rescarch Principles and Quantitative Metheds. The l ifetime Learning Publications. Belmont, $C A$

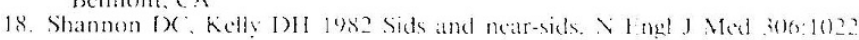
1028

19. Steinschncider A 1977 Prolonged sleep apnea and respirators instabilits: a discriminatise studi. Pediatrics $59 \cdot 9(0)-070$

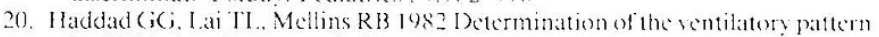
in RFM sleep in normal infants. J Appl Physiol $53: 52 \ldots 50$

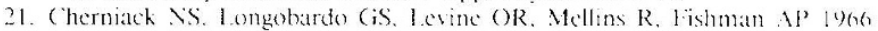
Periodic breathing in dogs J Appl Phwsiol 21:1847-1854

22. Thach BI, Broulletti RI, Abu-()sba YK Wilson SI Natem ()p 1980 Prevalence of mixed and obstructive apneic spells in preterm intants. Pediate Res 14:6.37(abstr)

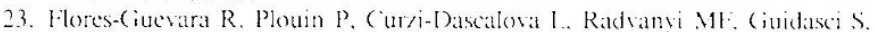
Pajot $\searrow$ Monod $\searrow 1982$ Slecp apneas in normal neonates and intants during the first 3 munthe of lite Veuropediatrics 13.21-28

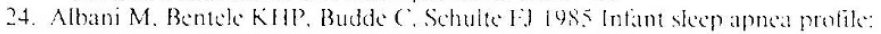
preterm is term infants. Fur J. Pediate 1+3:261-268

25. Kosch $P($ Stark AR $198+1)$ mamic maintenance of end-expitatory lung solume in full-term infants. $J$ Appl Phusiol $57: 1126-11.33$

26. Kosch P( . 1)avenport PW: Wozniah 1A. Starh AR l985 Reflex control of expiratory duration in full-term newhorn infiants. I Appl l'hsiol 56.575 . 581

27. Harding R. Johnson P. Mcclclland MII 1980 Respiratory function of the larynx in the deweloping sheep and the influence of slecp state. Resper Physul $4(0): 16,5-179$

28. Krauss A.V. Auld PAM 1969 Ventilators perfusion abnomalities in the promature infant: triple gradient. Pediatr Res $3: 25:-26.4$ 